\title{
Retrograde amnesia induced by carbon dioxide inhalation
}

ELTON E. QUINTON 1

UNIVERSITY OF CALIFORNIA AT LOS ANGELES

Rats were administered either air, $30 \% \mathrm{CO}_{2}$, or $50 \% \mathrm{CO}_{2}$ for $2 \mathrm{~min}$., $7 \mathrm{~min}$, or $15 \mathrm{~min}$. immediately following completion of a "one-trial" conditioning procedure. It was found upon testing $24 \mathrm{hr}$. later that both concentrations of $\mathrm{CO}_{2}$ produced retrograde amnesia, and that $50 \% \mathrm{CO}_{2}$ had a greater amnesic effect than did $30 \% \mathrm{CO}_{2}$. Increasing the duration of administration increased the degree of amnesia only in the groups receiving $30 \% \mathrm{CO}_{2}$.

Leukel \& Quinton (1964) have studied the effects of post-trial anesthesia induced by $\mathrm{CO}_{2}$ inhalation on the acquisition and extinction of an avoidance response. They concluded that the post-trial anesthesia did not produce a retrograde impairment of learning, but rather retarded subsequent performance because the $\mathrm{CO}_{2}$ treatment acted as an aversive stimulus.

It seems possible, however, that the $\mathrm{CO}_{2}$ treatments could have had both aversive and amnesic qualities, as has been shown to be the case when electroconvulsive shock (ECS) treatments are given (Hudspeth \& McGaugh, 1964). With ECS, the aversiveness of the treatment appears to develop with repeated treatment trials and masks the amnesic effects of the treatment. If this is also true of the $\mathrm{CO}_{2}$ treatment, then the multiple treatment procedure followed in the Leukel \& Quinton (1964) study would have only shown the aversive qualities of the treatment and not the amnesic qualities, if any.

The present study was designed to determine whether $\mathrm{CO}_{2}$ induced anesthesia can produce a retrograde impairment of learning in a situation where the aversive qualities of the treatment are held to a minimum, such as in a "one-trial" learning procedure. This study further attempts to determine whether depth and/or duration of anesthesia are variables effecting the degree of retrograde impairment.

Subjects

The Ss were 45 naive male albino rats (SpragueDawley) 90-110 days old at the start of the experiment. All Ss were maintained on a food deprivation schedule throughout the duration of the study. Each $S$ received approximately $15 \mathrm{gm}$ of dry laboratory chow per day immediately after each daily session.

\section{Procedure}

Training. The training procedure used in this study is similar to the one employed by Pearlman, Sharpless, \& Jarvik (1961), and Heriot \& Coleman (1962). In general, the procedure involves the suppression of a previously learned bar-pressing response as the result of an electric shock administered to the feet of the animal while in the act of bar-pressing. The Ss were trained to press a bar for food pellets in a Skinner box on a continuous reinforcement schedule. Once the bar-press was established, they were trained for 10 min. a day until a stable rate of pressing was attained. The criterion of stability was that the number of presses on the final day did not deviate by more than $10 \%$ from the mean of the previous four days. On the day following the achievement of the criterion, the animal was allowed to respond in the Skinner box as before for $5 \mathrm{~min}$., then the grid floor of the box was electrified with $600 \mathrm{v} \mathrm{AC}$ $(2.4 \mathrm{ma})$ for $2 \mathrm{sec}$. All Ss remained in the training apparatus for $10 \mathrm{sec}$. after being shocked, then they were placed in a desiccating jar and given their respective gas treatments. The trial-to-treatment interval was not more than $30 \mathrm{sec}$. After the treatment, they were removed from the jar and placed in their home cages to recover.

Treatment. Each group of five animals was given one of three concentrations of $\mathrm{CO}_{2}$ (i.e., three levels of anesthesia) for one of the three durations. Each rat was randomly assigned to one of the nine treatment groups before bar-press training. The concentration of $\mathrm{CO}_{2}$ in the atmosphere of a desiccating jar was regulated by controlling the rate of flow of $\mathrm{CO}_{2}$ and $\mathrm{O}_{2}$ into the jar. The total flow rate of both gases was a constant 9.4 liters per min., and the concentration of each gas is expressed as its percentage flow rate of this constant rate.

The three concentrations of $\mathrm{CO}_{2}$ used were $.04 \%$ (air only), $30 \%\left(70 \% \mathrm{O}_{2}\right)$, and $50 \%\left(50 \% \mathrm{O}_{2}\right)$. The three groups receiving $.04 \% \mathrm{CO}_{2}$ (air) served as control groups. That $30 \% \mathrm{CO}_{2}$ and $50 \% \mathrm{CO}_{2}$ do produce different levels of anesthesia in the rat was shown by Woodbury et al (1958) and Woodbury \& Karler (1960).

The duration of anesthesia was controlled by regulating the time each animal was exposed to the gas mixture in the jar. Each animal was in the jar for either $2 \mathrm{~min} ., 7 \mathrm{~min}$., or $15 \mathrm{~min}$. All animals regained the righting reflex within $3 \mathrm{~min}$. after being removed from the jar. No convulsive activity was observed in the animals either during or after the treatment.

Test. Each $\mathrm{S}$ was tested for the response suppression $24 \mathrm{hr}$. after it received the shock and treatment. It was placed in the Skinner box and allowed to bar-press on a continuous reinforcement schedule for $10 \mathrm{~min}$., as during training. The magnitude of the suppression effect was measured by expressing each S's performance during this period as a percentage of its normal rate of pressing. The latter value was calculated by averaging 
the S's performance on the last four $10 \mathrm{~min}$. sessions before the shock. The statistical tests were performed on these percentages. Thus, the presence of any amnesic effects would be indicated by more responses during the test period, as compared to the control period, and a higher percentage value.

\section{Results and Discussion}

An $F \max$ test performed on the cell variances was not significant at the .05 level $(F=31.85)$, therefore, no transformation was performed. All three a priori comparisons among the main effect totals for concentration were significant at beyond the .001 level (30\%-.04\%, $\mathrm{F}=23.35 ; 50 \%-.04 \%, \mathrm{~F}=83.05 ; 50 \%-30 \%, \mathrm{~F}=18.35)$. None of the comparisons among the main effect totals for duration reached the .05 level of significance, nor did the overall $F$ for duration. The interaction was also not significant.

In Fig. 1 are plotted the mean percent bar-presses occurring during the test session, as compared to the control sessions, for each of the nine treatment groups. The increase in degree of retrograde impairment with increasing concentrations of $\mathrm{CO}_{2}$ is apparent from these data. Furthermore, it appears that increasing the duration of anesthesia increased the degree of impairment in the animals receiving $30 \% \mathrm{CO}_{2}$. A Newman-Keules

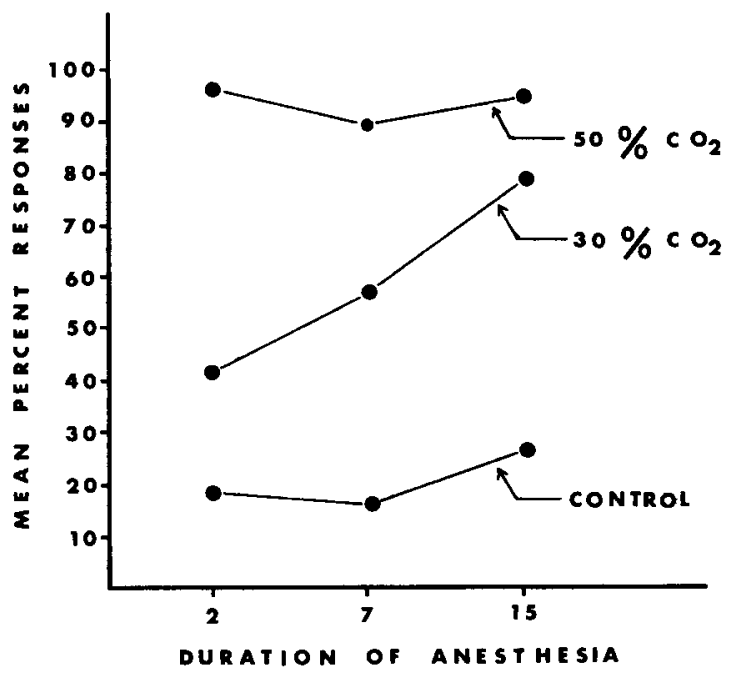

Fig. 1. Each point on the graph represents the mean percent bar-presses occurring during the test session, as compared to the control sessions, for one of the nine treatment groups. test for means within a logical grouping indicated that the group receiving $30 \% \mathrm{CO}_{2}$ for $15 \mathrm{~min}$. made more bar-presses during the test session, as compared to its control session, than did the group receiving $30 \%$ $\mathrm{CO}_{2}$ for $2 \mathrm{~min}$. ( $\left.\mathrm{p}<.05\right)$. Increasing the duration of anesthesia did not seem to affect the mean performance of the animals receiving $50 \% \mathrm{CO}_{2}$.

The data clearly indicate that rapidly induced posttrial anesthesia produced by $\mathrm{CO}_{2}$ inhalation can cause retrograde amnesia, and that the depth of anesthesia determines to some extent the degree of the amnesic effect. The effect of duration of anesthesia seems to depend upon the depth of anesthesia. At deeper levels of anesthesia, increasing the duration seems to have little effect, whereas at higher levels of anesthesia increasing the duration of anesthesia seems to increase the amnesic effect of the anesthesia.

Thus, it would seem that when an anesthetic agent is used to study retrograde amnesia, or "consolidation," one must consider not only where the agent acts and the speed of onset of its anesthetic action, but also the depth and duration of the anesthesia produced. With $\mathrm{CO}_{2}$, the latter two variables can be rather precisely controlled, and it produces anesthesia within seconds. Therefore, it would seem that $\mathrm{CO}_{2}$ is a promising research tool when used with one-trial learning techniques.

\section{References}

Heriot, J. T., \& Coleman, P. D. The effect of electroconvulsive shock on retention of a modified "one-trial" conditioned avoidance. J. comp. physiol. Psychol., 1962, 55, 1082-1084.

Hudspeth, W. J., \& McGaugh, J. L. Aversive and amnesic effects of electroconvulsive shock. J. comp. physiol. Psychol., 1964 $57,61-64$.

Leukel, F., \& Quinton, E. Carbon dioxide effects on acquisition and extinction of avoidance behavior. J. comp. physiol. Psychol., $1964,57,267-270$.

Pearlman, C. A., Jr., Sharpless, S. K., \& Jarvik, M. E. Retrograde amnesia produced by anesthetic and convulsant agents. $J$. comp. physiol. Psychol., 1961, 54, 109-112.

Woodbury, D. M., \& Karler, R. The role of carbon dioxide in the nervous system. Anesthesiology, 1960, 21, 639.

Woodbury, D. M., Rollins, L. T., Gardner, M. D., Hirischi, W. L., Hogan, J. R., Rallison, M. L., Tanner, G. S., \& Brodie, D. A. Effects of carbon dioxide on brain excitability and electroyltes. Amer. J. Physiol., 1958, 192, 79.

\section{Note}

1. Public Health Service Predoctoral Trainee, U.S.P.H.S. grant 5-TI-MH-6666 to the Department of Psychology, University of California at Los Angeles. 